\title{
Magnetic resonance imaging in dementia of Parkinson's disease
}

\author{
STEVEN J HUBER, * EDWIN C SHUTTLEWORTH,* JEFFREY A CHRISTY,* \\ DONALD W CHAKERES, $\dagger$ ANDREW CURTIN, $\dagger$ GEORGE W PAULSON*
}

From the Ohio State University College of Medicine Departments of Neurology* and Radiology $\dagger$ Columbus, Ohio, USA

SUMMARY The possibility that dementia in Parkinson's disease is associated with specific cerebral abnormalities identifiable by magnetic resonance imaging (MRI) was examined. Sixty eight patients with Parkinson's disease and 28 age and education matched normal controls were evaluated using neuropsychological procedures that included assessment of language, memory, cognition, visuospatial skills and mood. Twenty three patients $(34 \%)$ were found to have developed significant impairment in at least three of the five areas, thus meeting criteria for a dementia syndrome. Eleven patients $(16 \%)$ had no intellectual impairment and thirty four patients $(50 \%)$ had a mild to moderate intellectual disturbance. Patients with $(n=10)$ and without dementia $(n=20)$, matched for severity of Parkinson's disease, and normal controls $(n=10)$ matched for age with the two patients groups, were evaluated by MRI. MRI scans were analysed for evidence of generalised cerebral atrophy, ventricular enlargement, visualisation of the substantia nigra and severity of focal brain lesions. Results indicated that the presence of dementia in patients with Parkinson's disease was not associated with any specific pattern of MRI abnormalities.

Dementia in Parkinson's disease is probably the most controversial of the common dementia syndromes. It has been estimated that from $20 \%$ to $90 \%$ of patients with Parkinson's disease develop dementia. ${ }^{1-8}$ At least some of this variability among reports may be attributed to the lack of standardised criteria to define dementia and to differences in methodology for such assessment. Anatomic correlates of dementia in Parkinson's disease are also not well understood. Cortical atrophy and ventricular enlargement have been identified using computed tomography (CT) in some patients with Parkinson's disease, ${ }^{9-11}$ but the relationship between such radiological findings and the presence of dementia in Parkinson's disease are inconsistent. ${ }^{912-16}$

We examined possible anatomic correlates of dementia in Parkinson's disease using magnetic resonance imaging (MRI). MRI is superior to CT for visualisation of many cerebral abnormalities, ${ }^{17} 18$ par-

Correspondence to: Steven J Huber, Department of Neurology, Room 425, Means Hall, 1654 Upham Drive, Columbus, Ohio 43210, USA.

Received 7 June 1988 and in revised form 10 March 1989. Accepted 22 March 1989 ticularly in the search for periventricular white matter abnormalities which may be related to dementia. ${ }^{190}$ We defined the dementia syndrome according to criteria of Cummings and Benson, ${ }^{21}$ using objective neuropsychological procedures and statistical comparison with appropriate normal controls.

\section{Methods}

Subjects

Sixty-eight patients with idiopathic Parkinson's disease and 28 normal controls (spouses of the patients) participated. The patients had a mean age of 66.2 years (range 43 to 82 ) and an average of 14.4 years of formal education (range 9 to 22). Normal controls had a mean age of 67.2 years (range 52 to 79) and 13.6 years of formal education (range 9 to 18). Patients with Parkinson's disease were stabilised on antiParkinsonian medication at the time of study, and neuropsychological testing was conducted when medication was at peak efficacy. Patients taking anticholinergics (such as trihexyphenidyl) were excluded because of possible impairment of mentation. ${ }^{22}{ }^{23}$ None of the patients had a prior history of stroke or thalamotomy. All subjects and/or family members gave informed consent after the procedures were explained.

Neuropsychological Evaluation

1. Mini-Mental State Examination (MMSE). This is a brief 
evaluation of mental functioning,,$^{24}$ which correlates well with more extensive assessments of intellectual performance such as the Wechsler Adult Intelligence Scale. ${ }^{25}$ Subtests include orientation, registration, calculation, memory, and language. This measure has a maximum score of 30 .

2. Visuospatial Skills. In the Raven's Progressive Matrices task, ${ }^{26}$ subjects were presented with a systematic visual array with a blank area and with six alternatives, of which only one completes the pattern. Impairment on this task indicates disturbance of reasoning utilising visuospatial data. Visuospatial skills were also assessed by a block design task from the Wechsler Adult Intelligence Scale. ${ }^{27}$ This procedure evaluates visuospatial constructional abilities.

3. Mood. Severity of depressive symptoms was quantified using the Beck Depression scale. ${ }^{28}$ This is a self-rating scale which evaluates 21 symptoms related to depression on a scale of 0 to 3 .

4. Memory. Auditory verbal immediate memory was assessed by the digits-forward procedure. ${ }^{27}$ Auditory verbal acquisition memory was assessed using the paired-associates technique. $^{29}$ The distractor procedure ${ }^{30}$ was also used as a measure of acquisition memory. In this procedure, three consonants are presented, followed immediately by a distractor task of counting backwards from 100 by 3s. The distractor task lasts 10 seconds and is intended to prevent rehearsal of the to-be-remembered items prior to recall. Remote memory, defined as retrieval of information acquired prior to onset of disease, was evaluated by the standardised procedure developed by Albert and associates. ${ }^{31}$ 5. Cognition. Assessment of cognition included the calculation subtest of the MMSE ${ }^{24}$ and judgment of the similarities and differences listed in Cummings and Benson (ref 21, p.30) and Strub and Black (ref 32, p.112).

6. Language. Verbal fluency ${ }^{33}$ was tested by asking subjects to generate as many words as possible that begin with the letters $S$ and $P$ in 60 seconds. Significant impairment on this task may indicate impaired or slowed phonemic retrieval from long-term memory. ${ }^{34}$ Auditory verbal comprehension was assessed by the comprehension and commands subtests of the Western Aphasia Battery. ${ }^{35}$ Vocabulary was assessed by asking subjects to identify one of four outline drawings of objects named by the experimenter. Ten sets were used. In the naming task, subjects were asked to identify outline drawings of common objects. Twenty drawings were used. Significant impairment on the latter test suggests the presence of anomia, possibly visual agnosia, or both.

7. Apraxia. Subjects were asked to perform five common motor sequences (for example threading a needle) ${ }^{36}$ Inability to perform these actions on command was considered indicative of ideomotor apraxia. Because of the possible influence of akinesia, interpretation of these data is not straightforward and this was not included in the diagnosis of dementia.

In order to meet the Cummings and Benson ${ }^{21}$ criteria for dementia, there must be an acquired and persistent impairment of intellect as judged by family members. The impairment of intellect must be reasonably generalised, defined by significant impairment in at least three of the following five areas: memory, visuospatial skills, cognition, mood, or language. Impairment in each of the five areas for the individual patient was determined by comparison with normal control performance. Significant impairment was defined as any score on a neuropsychological measure that was at least two standard deviations below mean control performance. Patients with significant impairment in three or more areas met criteria for dementia, those with one or two areas of impairment were classed as having mild to moderate intellectual disturbance, and those with no intellectual impairment were classed as normal.

\section{MRI Evaluation}

Patients were imaged on General Electric 1.5 Tesla Signa System using routine spin echo pulse sequences. Sagittal and coronal images were obtained with TR of 600-800 and TE of $20 \mathrm{~ms}$. Axial images were obtained with a spin echo technique of TR 3000 , and echo delays 30 and $80 \mathrm{~ms}$ using flow compensation gradients. All slices were $5 \mathrm{~mm}$ thick with a 1 $\mathrm{mm}$ inter slice gap and a field of view of $20 \mathrm{~cm}$. Axial images were obtained with a $256 \times 256$ matrix while the other scans were obtained with a $256 \times 128$ matrix technique. A single excitation was used for all the studies.

Morphological measurements of cisternal and ventricular spaces were made using computer generated visual image analysing system. The $\mathrm{cm}$ scale which is recorded on each image was entered into the computer for proper scale conversion. Ventricular measurements were obtained from the short TR TE spin echo coronal image centred at the level of the foramen of Monro. Measurements included the distance between the most lateral portions of the frontat horns, the distance between the medial surfaces of tho caudate nuclei, the distance from the midline of the thirdo ventricle to the surface of the insula and the width of the thirdi ventricle (fig 1). Total surface area of the brain at this leve

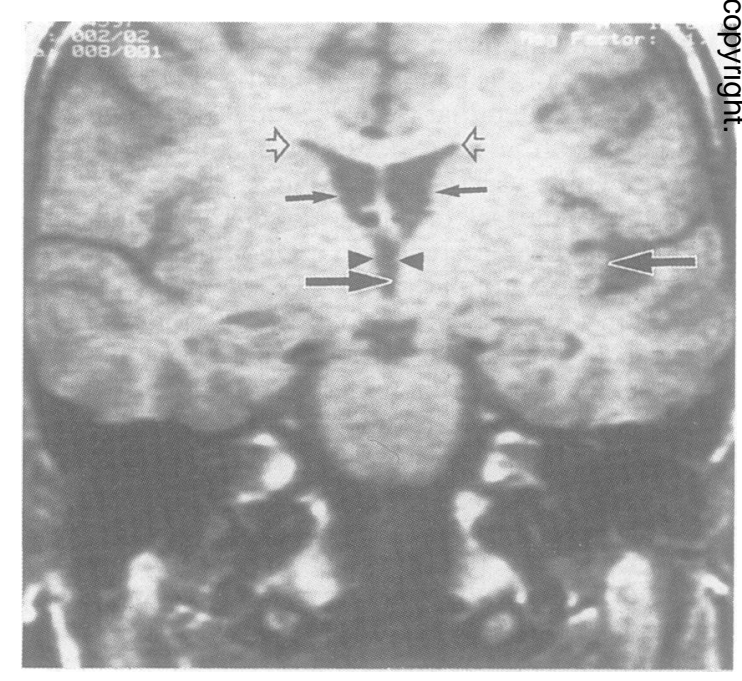

Fig 1 The four measurements of cisternal and ventricular spaces as shown on a normal coronal MRI. Distance between lateral margins of the frontal horns (open arrows), ventricular size at the level of the caudate nuclei (small closed arrows), distance from the midline to surface of the insula (large arrows), and the width of the third ventricle (arrow heads). 

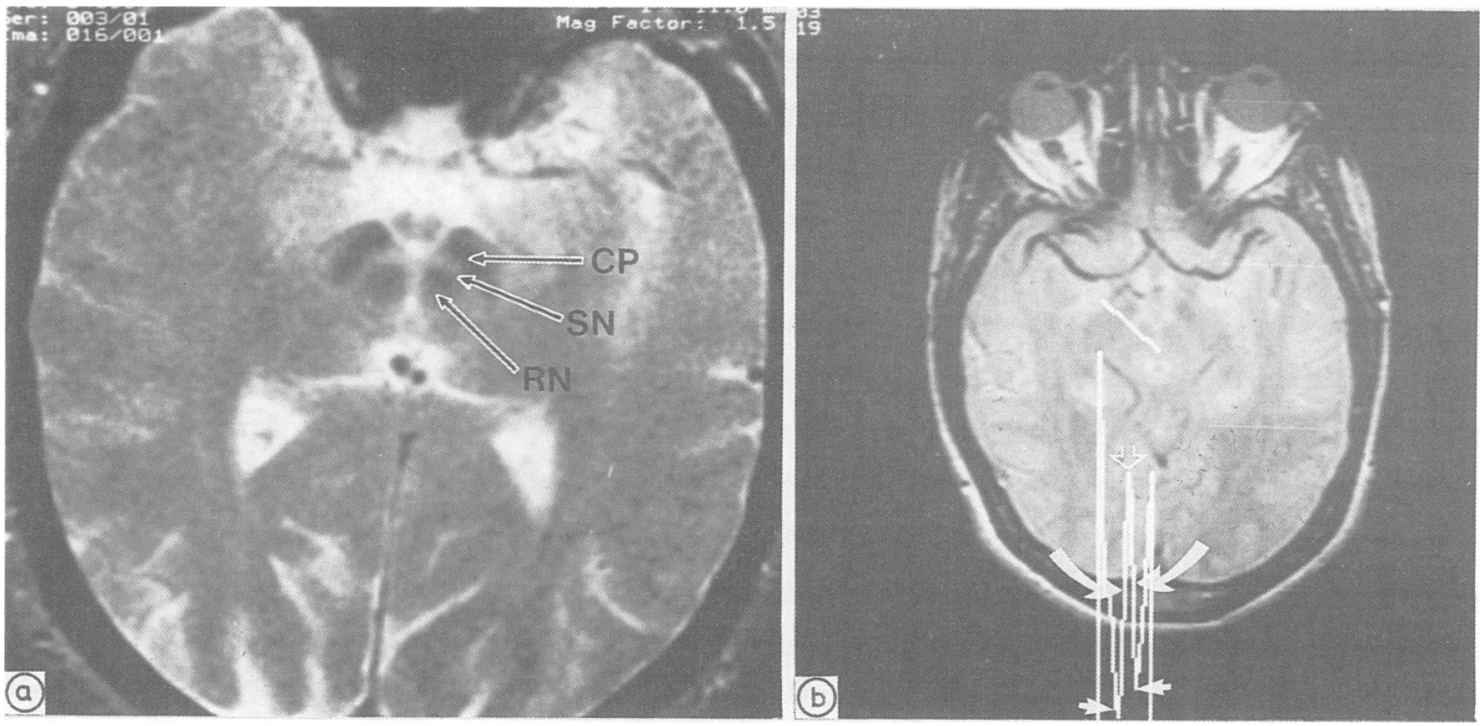

Fig 2 (A) Spin echo axial MRI (TR 3000 TE $80 \mathrm{~ms}$ ) of the pars compacta portion of the substantia nigra. The structures labelled include the cerebral peduncle $(C P)$, substantia nigra $(S N)$, and red nucleus $(R N)$. (B) A histoscan of the pixel intensities across the cerebral peduncle, substantia nigra and red nucleus. The signal peak for the substantia nigra (open arrows), low signal regions at the extreme of the peak (closed arrows) and the width at half maximum (curved arrows), are shown.

was also calculated by subtracting the area of the ventricles from the total surface area. This was used as a gross measure of brain atrophy.

Both the number and total surface area of high signal lesions on the spin echo TR 3000 TE 80 images were evaluated. Measurements of lesions from the supratentorial and infratentorial compartments were recorded separately. Again the $\mathrm{cm}$ scale from each scan was used as a scaling factor.

The TR 3000 TE 30 and 80 images at the level of the substantia nigra were reviewed directly on the computer image console (fig 2A). A computer generated histographic plot of the absolute signal pixel intensities of a strip of tissue 5 pixels thick extending perpendicularly across the right substantia nigra was generated (fig 2B). The strip extended from the cerebral peduncle, through the substantia nigra, and ended in the red nucleus. The lowest signal value in pixels from the red nucleus and the cerebral peduncle were averaged to generate a background measurement. This background signal intensity value was divided into the signal intensity value for the highest pixel value of the pars compacta. The ratio is proportional to the degree to which the absolute pixel number of the pars compacta was brighter than the adjacent tissues. If the signals of the pars compacta was identical to the surrounding tissues, the ratio would be 1.00 , and as the pars compacta became more intense than the surrounding tissues the ratio would increase. The width of the signal from the pars compacta was also measured in pixels at half maximum height of the signal (fig 2B). Each pixel is $0.39 \mathrm{~mm}$ for a $512 \times$ 512 extrapolated matrix image.

\section{Results}

\section{Neuropsychological evaluation}

Performances of all patients with Parkinson's disease and of normal controls on each of the neuropsychological procedures were analysed using Student's $t$ test to detect specific group differences. These data are presented in table 1. The patient and control groups were not significantly different in terms of either age, $t(94)=0.6$, or years of education, $t(94)=1 \cdot 1$. There was a significant impairment of overall mental performance as measured by the MMSE in the patients with Parkinson's disease, $t(91)=5.23, p<0.0001$.

As a framework to describe specific cognitive impairments that may contribute to the overall intellectual disturbance present in patients with Parkinson's disease, each of the five areas of neuropsychological function defined in the criteria for dementia by Cummings and Benson ${ }^{21}$ will be described separately.

There was not a significant difference between patients and controls for immediate memory (digit span) performance, $t(94)=1 \cdot 1$. Patients with Parkinson's disease had significant impairment of acquisition memory as measured by paired - associates (total) $t(94)=4.50, p<0.0001$, and both the easy items, $t(79)=3.5, p<0.0007$, and the hard items, $t(94)=$ 
Table 1 Mean (SEM) for patients with Parkinson's disease and normal controls on neuropsychological procedures

\begin{tabular}{|c|c|c|c|}
\hline Measure & Controls $(n=28)$ & Parkinson's disease $(n=68)$ & t-ratio \\
\hline $\begin{array}{l}\text { Age } \\
\text { Education } \\
\text { Mini-mental State } \\
\text { Orientation } \\
\text { Registration } \\
\text { Calculation } \\
\text { Recall } \\
\text { Language } \\
\text { Fluency } \\
\text { Naming } \\
\text { Vocabulary } \\
\text { Comprehension } \\
\text { Commands } \\
\text { Matrices } \\
\text { Blocks } \\
\text { Similarities } \\
\text { Digits-Forward } \\
\text { Paired Associates } \\
\text { Easy } \\
\text { Hard } \\
\text { Distractor } \\
\text { Remote } \\
\text { Depression } \\
\text { Apraxia }\end{array}$ & $\begin{array}{r}67.2(1.2) \\
13.6(0.4) \\
28.0(0.3) \\
9.9(0.1) \\
3.0(0.0) \\
4.4(0.2) \\
1.7(0.2) \\
9.0(0.0) \\
13.4(0.8) \\
19.3(0.2) \\
10.0(0.0) \\
5.0(0.0) \\
5.0(0.0) \\
10.6(0.2) \\
5.9(0.3) \\
6.5(0.3) \\
6.5(0.2) \\
14.3(0.7) \\
8.3(0.2) \\
6.0(0.6) \\
19.5(1.2) \\
27.2(1.6) \\
4.1(0.6) \\
5.0(0.0)\end{array}$ & $\begin{array}{r}66.2(1.0) \\
14.4(0.4) \\
25.4(0.4) \\
9.5(0.2) \\
3.0(0.0) \\
3.2(0.2) \\
0.9(0.1) \\
8.9(0.1) \\
11.5(0.7) \\
18.4(0.3) \\
9.6(0.7) \\
4.9(0.3) \\
4.9(0.7) \\
8.9(0.3) \\
4.8(0.2) \\
4.2(0.3) \\
6.8(0.1) \\
10.4(0.5) \\
7.4(0.2) \\
3.0(0.3) \\
10.7(1.1) \\
20.0(1.4) \\
10.3(0.8) \\
4.9(0.3)\end{array}$ & $\begin{array}{l}0.59, \text { n.s. } \\
-1 \cdot 10, \text { n.s. } \\
5 \cdot 23, \text { p }<0.0001 \\
2 \cdot 86, \mathrm{p}<0.005 \\
\text { NA* } \\
4 \cdot 29, \mathrm{p}<0.0001 \\
3.45, \mathrm{p}<0.001 \\
\text { NA* } \\
1 \cdot 81, \text { n.s. } \\
2 \cdot 50, \mathrm{p}<0.01 \\
\text { NA* } \\
\text { NA* } \\
\text { NA* } \\
4 \cdot 59, \mathrm{p}<0.0001 \\
5 \cdot 14, \mathrm{p}<0.0001 \\
5 \cdot 17, \mathrm{p}<0.0001 \\
-1 \cdot 11, \text { n.s. } \\
4.45, \mathrm{p}<0.0001 \\
3.51, \mathrm{p}<0.0007 \\
4 \cdot 65, \mathrm{p}<0.0001 \\
5.48, \mathrm{p}<0.0001 \\
3.02, \mathrm{p}<0.003 \\
-6 \cdot 38, \mathrm{p}<0.0001 \\
\text { NA** }\end{array}$ \\
\hline
\end{tabular}

*NA signifies not analysed.

$4.7, p<0.0001$. Impairment of acquisition memory was also found on the Peterson and Peterson distractor procedure, $\mathrm{t}(74)=5.5, \mathrm{p}<0.0001$. There was also impairment of remote memory for the patients, $t(94)$ $=3.02, p<0.003$. Impairment of visuospatial skills was seen in patients with Parkinson's disease as measured by both Raven's matrices, $t(94)=4 \cdot 6, p<$ 0.001 , and the block design subtest of the WAIS, $t(70)$ $=5 \cdot 1, \mathrm{p}<0.0001$. There was impairment of cognition as measured by both the attention and calculation subtests of the MMSE, $t(81)=4.3, p<0.0001$, and performance on the similarities and differences tasks, $\mathrm{t}(94)=5.2, \mathrm{p}<0.0001$. Patients with Parkinson's disease were impaired on the object naming task, $t(90)$ $=2.5, \mathrm{p}<0.01$, which suggests the presence of wordfinding difficulty. No other measures of language, including verbal fluency, $t(74)=1 \cdot 8$, auditory verbal comprehension, $t(86)=0.35$, commands, $t(60)=$ $0 \cdot 30$, and vocabulary, $t(86)=1 \cdot 54$, were impaired in patients with Parkinson's disease. Finally, depression scores were significantly higher in patients with Parkinson's disease, $\mathrm{t}(63)=5.55, \mathrm{p}<0.0001$.

There was wide variation in mental status among the patients. Twenty-three patients (34\%) met Cummings and Benson ${ }^{21}$ criteria for the presence of a dementia syndrome. Of the remaining patients, 34 $(50 \%)$ had either one or two significant impairments (mild to moderate intellectual disturbance), and the remaining 11 patients $(16 \%)$ had no evidence of intellectual impairment.

There were specific clinical differences between Parkinson's disease patients with and without dementia. In terms of disease severity as measured byo $\vec{N}$ Hoehn and Yahr stage, ${ }^{37}$ the mean rating for patient? with dementia (3.0) was significantly greater compare@ 을 with those without dementia $(2 \cdot 4), z=2 \cdot 4, p<0.02 \stackrel{\infty}{\triangle}$ Patients with dementia also had a significantly longev $z$ mean (SEM) duration (years) of disease $9.5(1.3)$ vso $6.9(0.7), t(66)=3.6, p<0.0006$, and had a somewhat although not a significant, later age of disease onse $61 \cdot 2(1 \cdot 9)$ vs. $57 \cdot 1(1 \cdot 2), t(66)=1 \cdot 9, \mathrm{p}<0.06$.

\section{Analysis of MRI and dementia}

This analysis involved a comparison of three groups including 10 patients with Parkinson's disease and dementia, 20 patients with Parkinson's disease who were not demented and 10 normal controls. Normal controls were evaluated so that both the sensitivity and specificity of cerebral abnormalities could be examined. Ten patients who met criteria for dementia volunteered to have MRI, and we sought to obtain a roughly proportional number of volunteers from the other two groups. Severity of disease was not significantly different between the two patient groups as estimated by the Wilcoxon rank-sum procedure for independent samples. The three groups were not significantly different with respect to age, $F(2$, $37)=0 \cdot 8$.

The MRI findings are presented in table 2. Each of the MRI measures for the three groups was evaluated by analysis of variance and post-hoc comparisons (Newman-Keuls) where appropriate. Surface area of the brain at the level of the foramen of Monro was not significantly different among the three groups, $F(2$, 
Table 2 MRI findings of patients with Parkinson's disease (PD) and normal controls. Data are presented as mean (SEM)

\begin{tabular}{|c|c|c|c|c|}
\hline Measure & $\begin{array}{l}\text { Control } \\
(n=10)\end{array}$ & $\begin{array}{l}P D \\
\text { Nondemented } \\
(n=20)\end{array}$ & $\begin{array}{l}P D \\
\text { Demented } \\
(n=10)\end{array}$ & F-value \\
\hline $\begin{array}{l}\text { Total surface area }\left(\mathrm{cm}^{2}\right) \\
\text { Frontal Horns }(\mathrm{cm}) \\
\text { Inter Caudate Nuclei }(\mathrm{cm}) \\
\text { Midline to Insula }(\mathrm{cm}) \\
\text { Width of Third }(\mathrm{cm}) \\
\text { Supratentorial Lesions }\end{array}$ & $\begin{array}{l}83 \cdot 5(3 \cdot 6) \\
3 \cdot 6(0 \cdot 3) \\
2 \cdot 5(0 \cdot 2) \\
4 \cdot 6(0 \cdot 2) \\
0 \cdot 7(1 \cdot 1)\end{array}$ & $\begin{aligned} 84.4(3.0) \\
3.9(0 \cdot 2) \\
2 \cdot 6(0 \cdot 1) \\
4 \cdot 7(0 \cdot 1) \\
0 \cdot 7(0 \cdot 5)\end{aligned}$ & $\begin{array}{l}80 \cdot 1(4 \cdot 4) \\
4 \cdot 1(0 \cdot 2) \\
2.9(0 \cdot 2) \\
4 \cdot 6(0 \cdot 1) \\
0.9(0.9)\end{array}$ & $\begin{array}{l}0 \cdot 4, \text { n.s. } \\
1 \cdot 4, \text { n.s. } \\
1 \cdot 6, \text { n.s. } \\
0 \cdot 05, \text { n.s. } \\
1 \cdot 9, \text { n.s. }\end{array}$ \\
\hline $\begin{array}{l}\text { Supratentorial Lesions } \\
\text { Number } \\
\text { Total Surface Area }\left(\mathrm{cm}^{2}\right)\end{array}$ & $\begin{array}{l}19.0(9 \cdot 2) \\
11.7(6.9)\end{array}$ & $\begin{array}{l}24 \cdot 1(7.4) \\
11.0(5.5)\end{array}$ & $\begin{array}{l}12 \cdot 1(4 \cdot 2) \\
10 \cdot 1(7 \cdot 1)\end{array}$ & $\begin{array}{l}0.6, \text { n.s. } \\
0.01, \text { n.s. }\end{array}$ \\
\hline $\begin{array}{l}\text { Infratentorial Lesions } \\
\text { Number } \\
\text { Total Surface Area }\left(\mathrm{cm}^{2}\right)\end{array}$ & $\begin{array}{l}1.4(0.6) \\
1.5(1.3)\end{array}$ & $\begin{array}{l}1.6(0 \cdot 7) \\
0.2(0.08)\end{array}$ & $\begin{array}{l}1.4(0.9) \\
0.8(0.7)\end{array}$ & $\begin{array}{l}0.03, \text { n.s. } \\
1 \cdot 0, \text { n.s. }\end{array}$ \\
\hline $\begin{array}{l}\text { Substantia Nigra } \\
\text { Brightness on 1st echo } \\
\text { Brightness on 2nd echo } \\
\text { Width on 1st echo (pixels) } \\
\text { Width on 2nd echo (pixels) }\end{array}$ & $\begin{array}{l}1.2(0.02) \\
1 \cdot 3(0.05) \\
9 \cdot 8(1 \cdot 3) \\
6 \cdot 2(0.8)\end{array}$ & $\begin{array}{l}1.1(0.01) \\
1.3(0.03) \\
7.9(0.5) \\
6.4(0.6)\end{array}$ & $\begin{array}{l}1 \cdot 1(0.02) \\
1 \cdot 2(0.06) \\
8 \cdot 4(0.5) \\
4 \cdot 6(1 \cdot 5)\end{array}$ & $\begin{array}{l}1 \cdot 9, \text { n.s. } \\
1 \cdot 4, \text { n.s. } \\
1 \cdot 6, \text { n.s. } \\
0 \cdot 9, \text { n.s. }\end{array}$ \\
\hline
\end{tabular}

37) $=0 \cdot 04$. Ventricular measurements that included the distance between the frontal horns, $F(2,37)=1 \cdot 4$, the distance between the caudate nuclei, $\mathrm{F}(2,37)=1 \cdot 6$, the distance from the midline to the insula, $F(2$, $37)=0 \cdot 1$, and the width of the third ventricle, $F(2$, $37)=1 \cdot 9$, were also not significantly different among the three groups. The number of infratentorial lesions, $F(2,37)=0.03$, and the total surface area of these lesions, $F(2,37)=1 \cdot 0$, were not significantly different among the three groups. No group differences were seen with respect to either the number of supratentorial lesions, $F(2,37)=0 \cdot 6$, or their total surface area, $F(2,37)=0.01$. The relative brightness of the signal in the area of the substantia nigra on the first spin echo, $F(2,34)=1 \cdot 2$, and the second spin echo, $F(2,34)=1 \cdot 4$, were not significantly different among the three groups. No group differences were observed in the width of the substantia nigra on either the first spin echo, $F(2,34)=1 \cdot 6$, or the second spin echo, $F(2$, $34)=1 \cdot 0$. Three patients were excluded from the substantia nigra analysis due to loss of data as a result of technical difficulties.

\section{Discussion}

We examined the possibility that Parkinson's disease patients with and without dementia could be distinguished by a specific pattern of cerebral abnormalities using MRI. Diagnosis of dementia was made according to the criteria defined by Cummings and Benson. ${ }^{21}$ This was accomplished by use of objective neuropsychological testing and statistical comparison with age and education matched controls. The primary finding was that the presence of dementia in Parkinson's disease was not associated with any cerebral abnormalities that could be identified by MRI.

Previous research on this topic has almost exclusively examined the hypothesis that generalised cerebral atrophy is more severe in patients with Parkinson's disease and dementia compared with those without dementia. The findings have been inconclusive $^{92-16}$ and the reasons for this variability are not entirely clear. One possibility is that degree of cerebral atrophy is a difficult assessment in the elderly since there is a normal loss of brain tissue with age making the range of normal rather broad. Additionally, cerebral atrophy is very nonspecific and can occur as a result of general medical problems encountered in the elderly, such as renal failure, steroid therapy, or malnutrition.

It is also probable that differences in methodology used to categorise patients as demented or nondemented have added to the variability in reports of atrophy in dementia associated with Parkinson's disease. Unless standardised criteria for dementia and methods for such assessment are adopted, confusion will persist in research related to anatomic and other correlates of dementia in Parkinson's disease.

Two sets of criteria to define dementia are most popular. One is defined in the third edition of the Diagnostic and Statistical Manual (DSM-III) of Mental Disorders. ${ }^{38}$ These criteria may not be the most suitable for diagnosis of dementia in Parkinson's disease. Judgment regarding significant loss of social or occupational function, a mandatory finding in DSM-III criteria, can be made solely with reference to intellectual function in patients with dementia of the Alzheimer type, but can be caused by intellectual dysfunction, the movement disorder, or both in patients with Parkinson's disease. ${ }^{39} 40$

In the Cummings and Benson criteria, ${ }^{21}$ dementia is defined by the acquired and persistent impairment of at least three of five categories of neuropsychological disturbances including memory, language, visuospatial skills, cognition, and emotional or personality 
change, in an alert patient. These criteria can be implemented by use of objective neuropsychological procedures related to each of the five areas, and statistical comparison with normal controls. For research purposes, these objectively defined criteria would certainly facilitate communication among researchers interested in the concept of dementia in Parkinson's disease.

Using objective test performance based on these criteria, we found, as have others, ${ }^{81}$ wide variation of intellectual status among patients with Parkinson's disease, ranging from no impairment, through mild and isolated intellectual impairment, to severe and generalised dysfunction compatible with the diagnosis of a dementia syndrome. Twenty three of our patients $(34 \%)$ met criteria for dementia, an estimate in keeping with the majority of reports based largely on clinical impression. ${ }^{42}$ We also found that our demented patients were older, had had Parkinson's disease for a longer time and generally had a more severe disease. These findings are also consistent with previous reports. ${ }^{243}$ We found no clear evidence of language abnormalities or apraxia which is in keeping with clinical features of a subcortical dementia syndrome in Parkinson's disease. ${ }^{44-46}$

Some MRI findings deserve further comment. There was a high incidence of white matter lesions in the elderly normal controls. These findings probably reflect common if not normal age-related processes. Histological correlates have included enlarged perivascular spaces, myelin pallor and loosening of the cell packing, which have been reported in demented ${ }^{19} 20$ as well as normal elderly individuals. ${ }^{478}$ The MRI parameters of the substantia nigra were not sensitive even to the presence of Parkinson's disease. While this was not a part of the experimental design of the study, such a finding is of current interest. A recent report by Duguid $e^{2} \mathrm{al}^{49}$ found that a small sample of patients with Parkinson's disease could be distinguished from controls on MRI evaluation of the substantia nigra. Our data suggest that analysis of the substantia nigra by MRI did not provide data that were specific to patients with Parkinson's disease.

Our results suggest wide variation in mental status of patients with Parkinson's disease, ranging from normal function to severe and generalised impairment compatible with the diagnosis of a dementia syndrome, but that cerebral abnormalities detected by MRI are not sensitive to the presence of dementia in Parkinson's disease.

This project was supported in part by a grant from the United Parkinson Foundation.

\section{References}

1 Celesia GG, Wanamaker WM. Psychiatric disturbances in Parkinson's disease. Dis Nerv Syst 1972;33:577-83.

2 Lieberman A, Dziatoloski M, Kupersmith M, et al. Dementia in Parkinson's disease. Ann Neurol 1979;6:355-9.

3 Loranger AW, Goodell H, Lee JE, et al. Intellectual impairments of in Parkinson's syndrome. Brain 1972;95:405-12.

4 Martin WE, Loewenson RB, Resch JA, et al. Parkinson's disease: Clinical analysis of 100 patients. Neurology 1973;23:783-90.

5 Mindham RHS. Psychiatric symptoms in parkinsonism. J Neurol Neurosurg Psychiatry 1970;33:181-91.

6 Pollock M, Hornbrook RW. The prevalence, natural history and dementia of Parkinson's disease. Brain 1966;89:429-48.

7 Selby G. Long-term treatment of Parkinson's disease with L-dopa: A clinical study of 148 patients. In: Birkmayer W, Hornykiewicz $O$, eds. Advances in Parkinsonism. Basel: Switzerland Roche, $\frac{\mathscr{T}}{\vec{D}}$ 1976:473-82

8 Pirozzolo FJ, Hansch EC, Mortimer JA, et al. Dementia in Parkinson's disease: A neuropsychological analysis. Brain Cogn $\omega$ 1982:1:71-83.

9 Selby G. Cerebral atrophy and parkinsonism. $J$ Neurol Sci. 1968;6:517-59.

10 Steiner I, Gomori JM, Melamed E. Features of brain atrophy in $\vec{\omega}$ Parkinson's disease. Neuroradiology 1985;27:158-60.

11 Becker H, Schneider E, Harker H, et al. Cerebral atrophy in Parkinson's disease, represented CT. Arch Psychiatr Nervenkr ? 1979;227:81-8.

12 Schneider E, Fischer P, Jacobi P, Becker H, Harker H. The

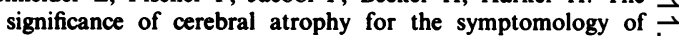
Parkinson's disease. J Neurol Sci 1979;42:187-97.

13 Portin R, Raininko R, Rinne UK. Neuropsychological disturba ces and cerebral atrophy determined by computerized tomogr $\vec{\oplus}$ phy in Parkinson patients with long-term levodopa treatmeri? In: Hassler RG, Christ JF, eds. Advances in Neurology. New York: Raven Press, 1984;40:219-27.

14 Inzelberg R, Treves T, Reider I, Gerlenter I, Korczyn AD. Computed tomography brain changes in Parkinsonian demes tia. Neuroradiology 1987;29:535-9.

15 Stroka H, Elizan T, Yahr M, Burger A, Mendoza M. Organic. mental syndrome and confusional states in Parkinson's disease Relationship to computerized tomographic signs of cerebra $\overrightarrow{0}$ atrophy. Arch Neurol 1981;38:339-42.

16 Pauletto D, Toso V. Cognitive performance and Parkinson disease: Neurolopsychological and CT study. Italian J Neuro Sci 1987;8:121-4.

17 Buonanno FS, Kistler JP, DeWitt LD, et al. Nuclear magnetic resonance imaging in central nervous system disease. Semirs Med 1983;4:329-38.

18 Go KG, Dyk P, Luiten AL, et al. Interpretation of nuclear magnetic resonance tomograms of the brain. $J$ Neurosurg 1983;59:574-84.

19 Johnson K, Davis K, Buonanno S, et al. Comparison of magnetic resonance and rotogen ray computed tomography in dementia. Arch Neurol 1987;44:1075-80.

20 Fazekas F, Chawluk J, Alavi A, Hurtig H, Zimmerman R. MR abnormalities at $1.5 \mathrm{~T}$ in Alzheimer's dementia and normal aging. AJNR 1987;8:421-6.

21 Cummings JL, Benson DF. Dementia: A Clinical Approach. Woburn, Mass: Butterworth Publishers Inc, 1983.

22 Koller WC. Disturbance of recent memory function in Parkinsonian patients on anticholinergic therapy. Cortex 1984;20 307-11.

23 Klawans HL. Behavioral alterations and the therapy of Parkin sonism. Clin Neuropharmacol 1982;5:29-38.

24 Folstein MF, Folstein SE, McHugh PR. Mini-mental state: A I practical guide for grading the mental state of patients for the clinician. J Psychiatry Res 1975;12:189-98.

25 McHugh PR, Folstein MF. Psychiatric syndromes of Huntington's chorea: a clinical and phenomenological study. In: Benson 
DF, Blumer D, eds. Psychiatric Aspects of Neurological Disease. New York: Grune \& Stratton, 1975.

26 Raven JC. Standard Progressive Matrices. New York: Psychological Corp, 1958.

27 Wechsler D. Wechsler Adult Intelligence Scale. New York: Psychological Corporation, 1945.

28 Beck AT. Depression. Philadelphia: University of Pennsylvania Press, 1967.

29 Wechsler DA. A standardized memory scale for clinical use. $J$ Psychol 1945;19:87-95.

30 Peterson LR, Peterson MJ. Short-term retention of individual verbal items. J Exp Psychol 1959;58:193-8.

31 Albert MA, Butters N, Levin J. Temporal gradients in the retrograde amnesia of patients with alcoholic Korsakoffs disease. Arch Neurol 1979;36:211-16.

32 Strub RL, Black FW. The Mental Status Examination in Neurology. Philadelphia: F A Davis, 1977.

33 Rosen WG. Verbal fluency in aging and dementia. $J$ Clin Neuropsychol 1980;2:135-46.

34 Matison R, Mayeux R, Rosen J, Fahn S. "Tip of the Tongue" phenomenon in Parkinson disease. Neurology 1982;32:567-70.

35 Kertesz A. The Western Aphasia Battery. New York: Grune and Stratton, 1982.

36 Christensen AL. Luria's Neuropsychological Investigation: Text, Manual, and Test Cards. Jamaica, NY: Spectrum Inc, 1975.

37 Hoehn MM, Yahr MD. Parkinsonism: Onset, progression, and mortality. Neurology 1967;17:427-42.

38 Williams J, ed. Diagnostic and Statistical Manual of Mental Disorders, 3rd ed. Washington: American Psychiatric Association, 1980.

39 Growdon JH, Corkin S. Cognitive impairments in Parkinson's disease. In: Yahr MD, Bergmann KJ, eds. Parkinson's Disease. Advances in Neurology. New York: Raven Press, 1986;45: 383-92.

40 Mayeux R, Stern Y, Rosen J, Fahn S. Is "subcortical dementia" a recognizable clinical entity? Ann Neurol 1983;10:278-84.

41 Al-Awar M, Becker JT, Hammond KM, Nekes R, Boller F. Learning deficit in Parkinson's disease: Comparison with Alzheimer's disease and normal aging. Arch Neurol 1987;44:180-4.

42 Brown RG, Marsden CD. How common is dementia in Parkinson's disease? Lancet 1984;i:1262-5.

43 Mortimer JA, Pirozzolo FJ, Hansch E, Webster DD. Relationship of motor symptoms to intellectual deficits in Parkinson's disease. Neurology 1982;32:133-7.

44 Albert M. Subcortical dementia. In: Katzman R, Terry RD, Bick $\mathrm{KL}$, eds. Alzheimer's Disease: Senile Dementia and Related Disorders. New York: Raven Press, 1978.

45 Cummings JL, Benson DF. Subcortical dementia: review of an emerging concept. Arch Neurol 1984;41:874-9.

46 Huber SJ, Shuttleworth EC, Paulson GW, et al. Cortical vs subcortical dementia: Neuropsychological differences. Arch Neurol 1986;43:392-4.

47 Brandt-Zawadski M, Fein G, VanDyke C, Kieinan R, Davenport L, DeGroot J. MR imaging of the aging brain: Patchy white matter lesions and dementia. AJNR 1985;6:675-82.

48 Zimmerman RD, Fleming CA, Lee BCP, et al. Periventricular hyperintensity as seen by magnetic resonance: Prevalence and significance. AJNR 1986;7:13-20.

49 Duguid JR, DeLa Paz R, DeGroot J. Magnetic resonance imaging of the midbrain in Parkinson's disease. Ann Neurol 1986;20:744-7. 